\title{
Las resoluciones de la Asamblea General de Naciones Unidas y la costumbre internacional
}

\section{The resolutions of the United Nations General Assembly and international custom}

\author{
Joaquín R. Argés \\ Doctor en Derecho \\ Universidad de Santiago de Compostela, España \\ arges@icaib.org
}

\section{Resumen}

El presente artículo estudia la cuestión de las fuentes del derecho internacional. Entre ellas, y de manera particular, se analiza la costumbre como fuente del derecho y su evolución desde el ius gentium clásico hasta las modernas formas de generar derecho consuetudinario a través de las prácticas internacionales de los Estados. En última instancia, la idea es reflexionar acerca de si ciertas decisiones de la Asamblea General de Naciones Unidas, cumpliendo determinados requisitos, pueden crear nuevas costumbres internacionales, y las consecuencias que pueden derivarse de ello.

\section{Palabras clave}

Costumbre internacional; Asamblea General; fuentes; ius gentium; Naciones Unidas.

\section{Abstract}

This article studies the question of the sources of international law. In particular, we analyze custom as a source of legislation. We take care of its evolution from the classical Ius Gentium to the modern ways of generating customary law through the governments' international practices. 
The idea is to reflect on whether certain decisions of the United Nations General Assembly that achieve some specifics can create new international customs. We also consider the consequences that may arise from these decisions.

\section{Keywords}

International custom; General Assembly; sources; Ius Gentium; United Nations.

\section{Resumo}

Este artigo aborda a questão das fontes do direito internacional. Entre eles, e de um modo particular, o costume é analisado como uma fonte de direito e sua evolução, desde o clássico ius gentium até os modos modernos de gerar o direito consuetudinário através das práticas internacionais dos Estados. Por último, analisa-se a possibilidade de que certas decisões da Assembleia Geral das Nações Unidas, que satisfazem certos requisitos podem gerar costume internacional e as consequências dê-lo.

\section{Palavras-Chaves}

Costume internacional; Assembleia Geral; fontes; ius gentium; Nações Unidas.

\section{Introducción}

El presente artículo estudia el tópico de las fuentes del derecho internacional, con especial atención en la costumbre internacional. Luego de repasar brevemente el sistema de fuentes del sistema jurídico internacional, hablamos del ius gentium y la costumbre como fuentes del derecho en sentido clásico. Posteriormente, nos centramos en las prácticas de los Estados surgidas a partir del siglo XX, es decir, la costumbre en sentido moderno.

Finalmente, tratamos la cuestión de si ciertas decisiones de la Asamblea General de las Naciones Unidas, en su carácter de órgano colegiado más

\footnotetext{
Cómo citar este artículo:

Argés, Joaquín R. (2021). Las resoluciones de la Asamblea General de Naciones Unidas y la costumbre internacional. Revista de la Facultad de Derecho y Ciencias Políticas, 51(134), pp. 239-260.

doi: https://doi.org/10.18566/rfdcp.v51n134.a10

Recibido: 10 de julio de 2019

Aprobado: 19 de octubre de 2020
} 
representativo del planeta, pueden generar derecho consuetudinario, y cuáles deberían ser los requisitos para que ello suceda.

Se trata de un tema importante, ya que, de aceptarse esta forma de creación jurídica, constituiría una herramienta muy poderosa para aportar soluciones, al menos en el campo jurídico, a grandes asuntos que afectan a la humanidad como un todo, y que a veces no son prioritarios en las agendas políticas de los Estados más poderosos e industrializados. Nos referimos a las crisis humanitarias, la protección del medio ambiente, la cuestión de las armas nucleares, la lucha contra la pobreza, la trata de personas, y otros importantes asuntos sobre los que se discute en las sesiones de la Asamblea General. Esto abre la posibilidad a que ciertas decisiones adoptadas con contundentes mayorías y suficientemente reiteradas puedan generar costumbre internacional con una fuerza jurídica vinculante para todos los Estados.

\section{El sistema de fuentes del derecho internacional}

La doctrina es pacífica en cuanto a que el sistema de fuentes formales del derecho internacional se encuentra descrito en el primer inciso del art. 38 del Estatuto de la Corte Internacional de Justicia ${ }^{1}$. Los autores (Diez de Velasco, 2009, pp. 120 y 121; Becerra Ramírez, 2017, p. 33) señalan que, en sentido estricto solo constituyen fuentes primarias, directas o principales los tres primeros apartados del inciso primero, es decir: los tratados, la costumbre y los principios generales del derecho. La jurisprudencia y la doctrina, por su parte, serían únicamente medios auxiliares.

Diez de Velasco destaca que existe un acuerdo en la doctrina al considerar que las fuentes directas tienen el mismo rango normativo, y que a priori no existe una jerarquía entre ellas. Prueba de ello sería su enumeración en

\footnotetext{
1 "Artículo 38. 1. La Corte, cuya función es decidir conforme al derecho internacional las controversias que le sean sometidas, deberá aplicar: a. las convenciones internacionales, sean generales o particulares, que establecen reglas expresamente reconocidas por los Estados litigantes; b. la costumbre internacional como prueba de una práctica generalmente aceptada como derecho; c. los principios generales de derecho reconocidos por las naciones civilizadas; d. las decisiones judiciales y las doctrinas de los publicistas de mayor competencia de las distintas naciones, como medio auxiliar para la determinación de las reglas de derecho, sin perjuicio de lo dispuesto en el Artículo 59. 2. La presente disposición no restringe la facultad de la Corte para decidir un litigio ex aequo et bono, si las partes así lo convinieren". Carta de las Naciones Unidas y Estatuto de la Corte Internacional de Justicia (1945) San Francisco: Naciones Unidas.
} 
letras (a, b y c), en vez de números, habiendo sido su intención dejar claro la inexistencia de prelación de una fuente sobre otra.

Sin embargo, para Becerra Ramírez, esta supuesta falta de jerarquía dentro de este art. 38-1 se contradice con lo discutido en el seno de la comisión de jurisconsultos que redactó el proyecto del Estatuto de la Corte Permanente de Justicia Internacional, en el que se hablaba de un "orden sucesivo", expresando una cierta jerarquía (2017, pp. 29-33). El autor destaca, igualmente, que la dinámica internacional actual es muy distinta que la que existía cuando el estatuto fue aprobado ${ }^{2}$.

Haremos a continuación algunos breves comentarios sobre las fuentes del derecho internacional. Comenzamos por los tratados internacionales y los principios generales del derecho, luego nos referiremos a la jurisprudencia y la doctrina. Para facilitar nuestra exposición, dejamos para el final la costumbre internacional, que es nuestro tema central.

\section{El tratado internacional}

La definición de tratado o convención internacional se encuentra descrita en el apartado a) del art. 2.1 de la Convención de Viena sobre el Derecho de los Tratados de 1969 (CVDT). El texto establece que son los acuerdos concertados entre Estados en forma escrita (ya sea en un único instrumento o en varios conexos), y regidos por el derecho internacional, sin importar la denominación que reciban (acuerdo, convención, carta, compromiso, concordato, modus vivendi, pacto, protocolo, estatuto, etc.).

Ha sido tal la importancia de este concepto cardinal de tratado en el ordenamiento jurídico internacional, que, desde sus orígenes, se defendió la tesis de que el ordenamiento jurídico internacional constituye un sistema de carácter horizontal y desprovisto de jerarquía normativa. Esta idea llevada a sus extremos desembocó en el paradigma que defendía, que el derecho internacional era eminentemente voluntarista, es decir, que dependía solo de la voluntad de los Estados, y que estos poseían una libertad casi ilimitada para concertar los acuerdos que estimaran adecuados. Uno de los argumentos más

2 Becerra Ramírez desarrolla también en este trabajo lo que denomina "las fuentes no incluidas en el art. 38-1" (2017, 91-134), entre las que analiza: los acuerdos de órganos internos, las resoluciones de organismos especializados, los actos unilaterales, las resoluciones de la Asamblea General, el soft law, las resoluciones del Consejo de Seguridad de la ONU y las resoluciones de órganos supranacionales. 
utilizados por los defensores de esta postura, es que, en el sistema internacional, los legisladores son los propios destinatarios de las normas, y que, por este motivo, la situación no era comparable con la de los ordenamientos internos.

Sin embargo, la aparición de las teorías sobre el requisito de licitud del objeto de los tratados internacionales -defendida desde fines del siglo XIX y con una gran cantidad de adeptos a partir de los inicios del siglo $\mathrm{XX}$ - puso en duda aquella idea de libertad ilimitada, y el carácter meramente voluntarista del ordenamiento internacional ${ }^{3}$.

Entre 1935 y 1937, el destacado internacionalista austríaco Alfred Verdross fue uno de los defensores de la necesidad de que el objeto de los tratados sea lícito y moralmente correcto para que estos sean válidos ${ }^{4}$. Igualmente, esta idea -como tantas otras- no era nueva, y ya se encontraba presente en el derecho romano. Así, el pasaje del Codex 2.3.6 del Corpus Iuris Civilis dice (García del Corral, I., 1892, p. 223):

El mismo Augusto á Basilia. Es punto indubitable de derecho, que los pactos que se hacen contra las leyes y las constituciones, o contra las buenas costumbres, no tienen fuerza ninguna. Publicada á 5 de las Calendas de Agosto, bajo el cuarto consulado de Antonino, Augusto, y el de Balbino.

Este pasaje del Codex se podía resumir, según el destacado comentarista Guittoncino de Sighipuldi -más conocido como Cino de Pistoia-, en la frase: "quod pacta que fiunt contra bonos mores non valent" (Pistoriensis, 1964), es decir, que los pactos contrarios a la buena moral carecen de valor ${ }^{5}$. Con el tiempo, numerosos autores de las más variadas tradiciones jurídicas también se pronunciaron acerca de la existencia de esta limitación ${ }^{6}$. Esta idea se fue

3 Entre los numerosos autores que han hablado de la importancia de la licitud del objeto de los tratados para que estos sean válidos se destacan: Chrétien, A. (1893, p. 330); Pradier-Fondéré, P. (1885, pp. 750-752); Rivier, A. (1896, pp. 57-62); Neumann, L. (1900, pp. 110-114). Algunos autores de mediados del siglo XVIII y principios del siglo XIX ya anticipaban la cuestión de la licitud del objeto de los tratados, entre ellos: Martens, G. (1821, pp. 105-107) y Heffter, A. G. (1857, p. 192).

4 Escribió al respecto varios artículos que tuvieron gran repercusión en su época, entre ellos: Anfechtbare und nichtige Staatsverträge (Verdross, 1935); Forbidden Treaties in International Law; Comments on Professor Garner's Report on: The Law of Treaties (Verdross, 1937a); y Trattati contra bonos mores (Verdross, 1937b).

5 Sus comentarios son del siglo XIV y pertenecen a su Lectura in Digestum vetus y Lectura in Codicem (1312-1314).

6 Entre los autores que hablan sobre la necesidad de que el objeto de los tratados sea lícito podemos mencionar a: August Wilhelm Heffter en Le Droit International Public de l'Europe (Berlín, 1853, pp. 174-176.); Alphonse Rivier en Principes du Droit de Gens, bajo el epígrafe De l'objet des traités (París, 1896, pp. 57-62); Leopoldo de Neumann, en Derecho internacional público moderno (Madrid, 
universalizando con el aumento exponencial de las relaciones internacionales, y con la creación de la Sociedad de Naciones, y en especial después, con la fundación de la Organización de las Naciones Unidas.

Una vez puesta en duda la horizontalidad del derecho internacional, quedó abierta la posibilidad de reconocer la existencia de normas de mayor jerarquía normativa internacional. La Carta de Naciones Unidas de 1945, que no deja de ser un tratado internacional, proclamó, de forma expresa, la primacía de ciertos principios del derecho internacional sobre los derechos internos, con un claro carácter constitucional.

Posteriormente, con la aprobación de la Convención de Viena sobre el derecho de los tratados, se produjo la positivación de la institución del ius cogens en su art. 53, este hito importante implicó confirmar la existencia de normas imperativas en el derecho internacional, y también la existencia de límites a la libertad de los Estados. Quedaba así echada por tierra la antigua idea de la exclusiva autolimitación de los Estados y el carácter eminentemente voluntarista del ordenamiento jurídico internacional, sugiriendo -al mismo tiempo- la posibilidad de un orden público internacional formado por normas de distinto rango, y, por lo tanto, una jerarquía normativa de derecho internacional.

El fundamento de la obligatoriedad de los tratados a día de hoy sigue siendo materia de debate. Para los iusnaturalistas, el fundamento de obligatoriedad del derecho internacional -al igual que de todo otro derecho positivo- se encuentra en el derecho natural. Los iuspositivistas, en cambio, lo encuentran en normas y principios ya positivizados.

En opinión de Diez de Velasco (2009, pp. 197-198) los tratados son vinculantes gracias a la existencia de los principios de pacta sunt servanda, de buena fe y el de primacía de la aplicación de los tratados internacionales sobre el derecho interno (art. 27 de la CVDT), satisfaciendo así la necesidad de seguridad jurídica, al haber sido reconocidos como reglas generales de derecho internacional universalmente aceptadas ${ }^{7}$. Para Becerra Ramírez (2017, p. 38) los tratados concluidos entre las partes, al ser fuente indiscutible del derecho internacional, deben ser obligatoriamente aplicados por el juez en la solución

1900, pp. 110-114), el tratadista francés Paul Fauchille, en su revisión al trabajo Traité de Droit International Public de Henry Bonfils, (París, 1908); o Paul Reuter en Principes de Droit International Public (Pays-Bas, 1962, pp. 431-656), entre muchos otros.

7 Estos principios también se encuentran recogidos en la CVDT en su art. 26. 
de controversias, incluso cuando no se trate de derecho convencional de aplicación general.

\section{Los principios generales del derecho}

Hablemos ahora brevemente de los principios generales del derecho como fuente del derecho internacional. Comenzamos con un enfoque iusnaturalista. El profesor Francisco Puy, iusfilósofo y catedrático de la Universidad de Santiago de Compostela, señala en su trabajo Las trampas del lenguaje jurídico y político (2014), que en el ámbito internacional los principios generales del derecho son fuente del derecho, pero no porque hayan sido reconocidos como tales por el Estatuto del Tribunal Permanente de Justicia Internacional, sino porque ya lo eran desde siempre ${ }^{8}$. En su opinión, los principios generales del derecho no son una fuente que pueda subsumirse en la doctrina legal de los tribunales, o en la producción legislativa, debido a que existen principios generales fuera del ordenamiento positivo.

Puy explica que estos principios generales del derecho internacional universal son los mismos que están en la base del derecho interno, y cuyo conjunto sigue en una cascada descendente, "formando todo ello el mismo derecho natural” (2014, p. 179). Estos principios -en opinión del profesor- no serían únicamente los principios contenidos en el derecho de gentes estricto (convencional y consuetudinario), sino que tienen una validez anteriory superior, porque no cumplen solamente una función de informar al ordenamiento, sino que, en realidad, le dan contenido o materia. Puy concluye, que los principios generales del derecho son derecho natural (2014, p. 180).

Por otro lado, y desde una visión iuspositivista moderada, el internacionalista Diez de Velasco (2009, p. 127) sostiene que no hay duda de que los principios generales del derecho forman parte del ordenamiento internacional positivo, en especial, desde su inclusión en el tantas veces referido art. 38 del Estatuto del TIJ ${ }^{9}$. En su opinión, la repetición de estos principios en diversos acuerdos, junto con la opinio iuris, forman la base consuetudinaria en el proceso de su positivación. Asimismo, cree que existe otro proceso de positivación de

8 La indicación del profesor al Estatuto del Tribunal Permanente de Justicia Internacional se debe a que, precisamente, el art. 38 de este instrumento fue el que primero positivizó los principios generales del derecho internacional y constituyó la fuente directa del art. 38 del Estatuto de la actual Corte Internacional de Justicia.

9 El destacado internacionalista utiliza la sigla TJI para referirse a la Corte Internacional de Justicia (CIJ), nombre que preferimos para diferenciarlo claramente de su antecesor: el Tribunal Permanente de Justicia Internacional. 
los principios generales, pero que opera por vía consuetudinaria, es decir, a través de la convicción jurídica y la repetición de actos en los ordenamientos. Defiende, también, que la concreción de estos principios en el ámbito internacional se realiza más comúnmente a través de las decisiones de los tribunales internacionales (Diez de Velasco, 2009, p. 127).

\section{La doctrina y la jurisprudencia}

Nos referiremos, de manera muy sucinta, a las fuentes secundarias, que se mencionan en el apartado d) del art. 38 del Estatuto. Para Diez de Velasco (2009, pp. 120-131) la doctrina y la jurisprudencia -entendida esta última como el conjunto de las decisiones de un sistema judicial- al constituir únicamente medios auxiliares, son incapaces de crear, modificar o extinguir una norma jurídica. Su misión sería, por lo tanto, la de auxiliar al juez y al intérprete en la determinación exacta del contenido de las normas jurídicas.

La doctrina no es otra cosa que la opinión de los publicistas en la materia, que conforman la denominada interpretación doctrinal y que se manifiesta de manera individual, en artículos y libros, o de manera colectiva, a través de debates, acuerdos y conclusiones de institutos científicos, por ejemplo, el Instituto de Derecho Internacional.

Para el profesor Puy (2014, p. 141), en cambio, si bien la jurisprudencia y la doctrina no crean normas en el sentido estricto de la palabra, sí crean derecho, porque el derecho no está formado únicamente de normas positivas.

Por nuestra parte, deseamos apuntar que, dentro de la doctrina, ocupan un importante lugar las opiniones disidentes y los votos razonados emitidos por los jueces de las cortes internacionales, en especial los de los miembros de la Corte Internacional de Justicia, debido a que, en numerosas ocasiones, estas opiniones influyen y mucho en posteriores interpretaciones.

Por último, es menester también incluir en este apartado de la doctrina los importantes aportes de la Comisión de Derecho Internacional de Naciones Unidas, que en su carácter de órgano jurídico especializado es la caja de resonancia de intensos debates en materia de teoría jurídica, que contribuye significativamente a la interpretación y a la creación jurídicas. Se busca lograr el consenso entre las tradiciones jurídicas más diversas de todo el mundo. Sus pronunciamientos gozan de gran legitimidad debido a que sus participantes son destacados juristas y son el resultado de muchos años de trabajo. 
En relación con la jurisprudencia, debemos hablar de la Corte Internacional de Justicia. En la actualidad no se discute la importancia de las decisiones del órgano jurisdiccional más importante del mundo. Sin embargo, el estatuto de la Corte, en su art. 59, establece que la obligatoriedad de sus decisiones es limitada, ya que solo afecta a las partes intervinientes y no puede extenderse de manera automática a casos análogos.

Una interpretación estricta de estas ideas significaría que las decisiones del máximo tribunal internacional -en su carácter de medio auxiliar- serían incapaces de crear, modificar o extinguir una norma jurídica. A pesar de ello, y como bien señala Diez de Velasco (2009, pp. 127-129), en la práctica, el propio tribunal siempre "siente respeto por su jurisprudencia anterior" y que esto necesariamente proyecta su influencia sobre los demás Estados. Becerra Ramírez (2017, p. 84), comparte esta postura, al mencionar que muchos fallos tienen una gran autoridad, porque se trata de resoluciones emitidas por juristas de una gran calidad que contienen elementos de análisis y reflexiones sobresalientes, que los colocan como un patrón a seguir.

\section{La costumbre como fuente del derecho internacional}

Nos centramos ahora en la costumbre internacional. Siguiendo al profesor Puy (2014, p. 159) podemos decir, que la costumbre jurídica es, en esencia, derecho no escrito o ágrafo, definido por la reiteración de actos o prácticas a las que se atribuye fuerza jurídica por la conciencia colectiva. El apartado b) del primer inciso del art. 38 del estatuto que venimos analizando la define como aquella que sirve como "prueba de una práctica generalmente aceptada como derecho".

Como es sabido, el derecho internacional fue en sus orígenes, un derecho eminentemente consuetudinario, ya que nació como un grupo de usos y prácticas internacionales.

En la actualidad, y a pesar de la existencia de una gran cantidad de tratados y convenciones internacionales, el valor jurídico de la costumbre internacional todavía juega un rol de importancia, que se manifiesta principalmente en la práctica internacional de los Estados. Pero, también es cierto que los tiempos han cambiado desde aquellos inicios incipientes del derecho internacional. Para comprender esta evolución, estimamos útil hablar de dos momentos del derecho internacional consuetudinario: el que corresponde a sus inicios desde el siglo XVI, que denominaremos ius gentium clásico; y el surgido de 
las prácticas internacionales de los Estados a partir del siglo XX, y que hemos llamado ius gentium moderno.

\section{El ius gentium clásico (siglos XVI y XVII)}

Desde épocas antiguas, la expresión ius gentium ha sido especialmente ambigua. Esta ambigüedad se ha visto claramente en la gran diversidad de significados y sentidos atribuidos a este tópico jurídico clásico desde el derecho romano ${ }^{10}$. Verdross $(1976$, p. 3) explica que el concepto de ius gentium en sentido romano, comprendía el derecho común de los pueblos de la antigüedad clásica. En épocas más recientes, la expresión ius gentium se ha utilizado también como sinónimo de derecho internacional en general ${ }^{11}$.

En el siglo XVI, con la destacada labor desarrollada por los miembros de la Escuela Teológico-Jurídica española, surgen los primeros estudios sistemáticos dedicados a definir el derecho internacional como ciencia ${ }^{12}$. En 1528, el teólogo y jurista español Francisco de Vitoria -considerado padre del derecho internacional- publica Relectio de potestate civil. En este trabajo, Vitoria sostiene que, si el derecho de gentes se deriva de modo suficiente del derecho natural, posee manifiesta fuerza para otorgar derecho y para obligar. Asimismo, cree que, incluso en el supuesto de que no siempre se derive del derecho natural, "parecería que se sigue del consenso de la mayor parte del orbe todo, primordialmente en favor del bien común de todos” (Vitoria, 1528/2008, p. 219).

Una década después, y partiendo de la noción del jurisconsulto romano Gayo, Vitoria señaló en su Relectio de indis que el derecho de gentes es derecho natural o se deriva de él, y que, según las Instituciones, es aquel que "la razón natural constituyó entre las gentes” (Vitoria, 1538/1967, p. 78). Vitoria vuelve

10 En un interesante trabajo sobre el significado del ius gentium durante la experiencia jurídica romana, el profesor italiano Gabrio Lombardi (1947, pp. 386-388) señala, que la utilización de la expresión ius gentium en el ámbito público terminó primando por la influencia de publicistas e historicistas. En su opinión, los investigadores de la Edad Media y Moderna, prescindiendo de las aplicaciones privatistas, se habrían visto influenciados por el mayor número de pasajes en los que el iuris gentium se refería a normas e institutos relativos a relaciones entre varios Estados.

11 Por ejemplo, puede mencionarse la voz alemana que terminó por imponerse para referirse al derecho internacional; esta es Völkerrecht, que literalmente significa "derecho del pueblo, derecho de gentes, ius gentium, en donde el prefijo Volk [fJlk] n (Volk(e)s; Völker) quiere decir "pueblo, nación, población, mundo, gente"; y Recht se traduce como "derecho".

12 La Escuela Teológico-Jurídica Española también ha sido denominada Escuela de Salamanca o Salmantina (siglos XVI y XVII), por ser este el sitio en donde se concentró mayormente su actividad académica. 
a insistir en esta obra, en que, si hubiera alguna ley humana, que, sin causa alguna, prohibiera lo que permite el derecho natural y divino, sería inhumana e irracional, y, por consiguiente, no tendría fuerza de ley (Vitoria, 1967, p. 80). Como es sabido, en su cátedra salmantina, Vitoria reintrodujo en las aulas la Suma teológica de Santo Tomás a través de su obra titulada De iustitia commentarium in secundam secundae (Vitoria, 1535/2001).

Al realizar sus comentarios sobre "si el derecho de gentes es lo mismo que el derecho natural” (La justicia, Cuestión 57, art. 3) Vitoria denunciaba la confusión histórica del concepto de ius gentium (Pereña, 1973). Este confusionismo habría sido provocado, para Vitoria, por causa de tres motivos. El primero de ellos sería el texto de Ulpiano, que hacía del ius gentium un derecho específicamente humano, diferenciado del derecho natural común a todos los animales. La segunda causa de confusión se debería a la definición descriptiva de San Isidoro, en la que se incluían numerosas instituciones que se encontraban vigentes en casi todos los pueblos.

Finalmente, el tercer motivo de confusión alegado por Vitoria se encontraría en el propio texto de Santo Tomás, que identificaba el ius gentium con las leyes positivas humanas que contienen conclusiones necesarias del derecho natural (Pereña, 1973, p. 23).

El profesor Luciano Pereña (1973, p. 24) explica que Vitoria se esfuerza por encontrar un criterio diferenciador que configure el ius gentium como derecho típicamente positivo, distinto del natural y del civil. Así, para el padre del derecho internacional, el ius gentium es ley universal, positiva, constitucional y obligatoria para todos los Estados que integran orgánicamente la comunidad del orbe.

En su carácter jurídico, el ius gentium comprende, entonces, normas que regulan las relaciones internacionales en dos sentidos: inter gentes (entre los pueblos) e inter homines (entre individuos de diferentes Estados). En cuanto a su universalidad, esta se debería a que es derecho vigente en todo el orbe (ius totus orbis). Y su positividad estaría dada, porque su fuente se encuentra en el común consentimiento de todas las naciones, por medio de costumbres, pactos y leyes. En conclusión, Vitoria hace derivar el ius gentium del consentimiento virtual de todo el orbe, aunque no haya sido formalmente convenido.

De esta forma, el ius gentium comprende, para Vitoria, el conjunto de normas jurídicas introducidas en el curso de la historia por la práctica continuada de las naciones, en cuanto miembros de la comunidad, y estas 
normas son susceptibles de cambio, evolución y derogación (Pereña, 1973, p. 25). En relación con su obligatoriedad, en opinión de Vitoria, el ius gentium es obligatorio a raíz del carácter orgánico de la comunidad del orbe, y tiene su fundamento en el derecho natural, siendo condición de su validez su conformidad con este último (Pereña, 1973, p. 26). Igualmente, el profesor de Salamanca reconoce que el ius gentium no siempre deriva del derecho natural, pero que también, en estos casos, este es útil y necesario en favor del bonus orbis, el bien común de todos (Vitoria, 1528/2008, p. 219).

Hablemos ahora de otro destacado integrante de la Escuela Española, que también se refirió al derecho de gentes: Domingo de Soto. En el año 1556, Soto publicó De iustitia et iure (De la justicia y del derecho). En su opinión, el derecho de gentes se distingue del derecho natural, porque aquel forma parte del derecho positivo, ya que es aquel en el que todos los hombres convienen. Por ello, creía que no podría ser derecho natural, ya que el derecho natural es común a todos. Sin embargo, para Soto (1556/1968, pp. 194-198) en el derecho de gentes también hay algunas cosas que no son dispensables, por ser cosas muy convenientes a la convivencia humana y nunca podrían obtener fuerza de ley los casos que contradigan al derecho natural.

Como síntesis de este período debemos mencionar a Francisco Suárez, considerado el más destacado miembro de esta Escuela de Salamanca, y brillante discípulo de Vitoria. En 1612, Suárez publica su tratado De legibus, en donde recoge su pensamiento sobre el ius gentium. En el final del libro II, explica que, en su opinión, existen dos tipos de derecho de gentes.

Por un lado, hay un derecho de gentes que tiene carácter mudable y cuya fuente de obligatoriedad es el reconocimiento por parte de los diferentes Estados, y que cada Estado puede derogar o modificar, siempre que no redunde en perjuicio y en injusticia para otro Estado. Por otro lado, el segundo tipo de derecho de gentes, sería aquel de carácter universal que tiene su origen en los usos y costumbres internacionales, y que puede ser modificado o derogado solamente con el acuerdo de todas o casi todas las naciones (totus orbis).

Para Suárez, el derecho de gentes constituye, entonces, una forma de ley intermedia entre el derecho natural y el civil. Así, el derecho de gentes coincidiría con el derecho natural, aunque dentro de ciertos límites, en la aceptación común, en su carácter universal y en la facilidad con que sus normas se deducen de los principios naturales. Y coincidiría con el derecho humano en que su necesidad o evidencia no son absolutas (Suárez, 1612/1973, Lib. II, pp. 146-149). 
El profesor Camilo Barcia Trelles (1934, pp. 82-84) explica que, para determinar las diferencias que existen entre el derecho natural y el derecho de gentes, Suárez partió de las cuatro opiniones que se habían defendido hasta ese momento: la que estaba inspirada en la definición de Ulpiano (que consideraba que el derecho natural se aplica a todos los seres vivientes y el de gentes solo al hombre); la que establecía que el derecho natural se conoce por la sola razón natural (pudiendo el derecho de gentes desentrañarse únicamente de modo discursivo y mediante inducciones); la que centraba la diferenciación en que el derecho natural es superior a la voluntad humana e independiente de la misma (siendo entonces el derecho de gentes aquel ligado a la voluntad humana); y la opinión que sostenía que la diferencia entre ambos radicaba en el carácter preceptivo del derecho natural y la naturaleza permisiva o concesiva del derecho de gentes.

Suárez valoró una a una estas opiniones. Con respecto al primer criterio diferenciador, concluyó que existen instituciones de derecho natural que solo son aplicables a seres razonables y no al resto de los animales, siendo entonces un criterio inservible.

En cuanto al segundo criterio diferenciador, que es el que sostiene que el derecho de gentes se conoce a través de múltiples y complicadas inducciones, Suárez explica que algunas instituciones del derecho de gentes son introducidas por el arbitrio o por el consentimiento de los hombres, y que el hecho de que se deriven del derecho natural no significa que formen parte del mismo (Barcia Trelles, 1934, p. 83).

El tercer criterio diferenciador que estudia Suárez es aquel que entiende que el derecho natural está por encima de la voluntad humana, y el derecho de gentes es necesaria e indefectiblemente producto de la voluntad de los hombres. En relación con este criterio, si bien es correcto que el derecho natural comprende cosas que existen sin la preexistencia de la sociedad humana y se deducen de la naturaleza, y al derecho de gentes pertenecen aquellas conclusiones que -deducidas de la naturaleza- presuponen la existencia de la sociedad humana y se dirigen a su conservación, en su opinión existen algunos principios de derecho natural que obligan solamente cuando existe una suposición previa o institución obra de los hombres (por ejemplo: no hurtar o cumplir con lo estipulado).

El cuarto criterio diferenciador entre el derecho natural y el derecho de gentes es el que se refiere a que el derecho natural sería siempre preceptivo, a diferencia 
del derecho de gentes, que sería solo de naturaleza permisiva o concesiva. Barcia Trelles (1934) explica que -ante este problema-Suárez considera que este criterio también es erróneo, ya que tanto la concesión de derechos, como la prohibición que de ella resulta, son de derecho natural. Así, por ejemplo, señala que no es el uso repetido el que engendra la costumbre, ya que el uso de un derecho no crea derecho, sino que es el derecho el que faculta el uso y, por lo tanto, crea la costumbre. Asimismo, según Barcia Trelles (1934, pp. 82-87) Suárez considera que, de una prohibición contenida en un derecho humano, nace una obligación, cuyo cumplimiento tiene su fundamento en el derecho natural, por ejemplo, la inviolabilidad de los embajadores, los tratados de paz, etcétera.

Luego de rechazar todos los criterios diferenciadores mencionados, Suárez llega a la plenitud del concepto del ius gentium, que clarifica, estructura y tipifica al final del segundo libro de su tratado, De legibus (Pereña, 1973, p. XLI). Existen, entonces, dos tipos de derechos de gentes. El primero, es el de carácter mudable, y otro que es universal y tiene su origen en los usos y costumbres internacionales, que solo puede ser modificado o derogado con el acuerdo de todas o casi todas las naciones (totus orbis).

En definitiva, para Suárez, el derecho de gentes coincide con el derecho natural (aunque dentro de ciertos límites) en la aceptación común, en su carácter universal y en la facilidad con que sus normas se deducen de los principios naturales. Pero, también, coincide con el derecho humano en que su necesidad o evidencia no son absolutas (Suárez, 1612/1973, pp. 146-149). En cuanto a la imperatividad del ius gentium, Suárez (1612/1973, pp. 142) explica que, al igual que todas las leyes humanas, los preceptos del derecho de gentes deben cumplir las exigencias de la equidad y de la justicia.

Es momento de referirnos a otro destacadísimo precursor del derecho internacional: el neerlandés Hugo Grocio. Entre 1604 y 1605, y desde una visión distinta de aquella de la Escuela Española, Grocio escribió una voluminosa obra titulada Die iure praedae commentarius (EI derecho de presa). En este trabajo, el jurista y diplomático realiza un análisis sobre la imperatividad y exigibilidad, tanto del derecho natural como del derecho internacional. Clasifica al derecho de gentes en primario (al que identifica con el derecho natural) y en derecho de gentes secundario o positivo, al que considera tal por tener carácter de mudable. En opinión de Grocio (1605/1987, pp. 26-30), la costumbre forma parte del derecho positivo, y como tal, no puede contravenir principios universales. Asimismo, las normas nacidas de pactos con el reconocimiento de todos los pueblos tienen carácter obligatorio. 
En 1609, se publica, de manera anónima, otra obra de Grocio, que llevó por título Mare Liberum (Grocio, 1609/1956). En 1625, y en respuesta a este trabajo, el profesor portugués Fray Serafim de Freitas escribió De iusto imperio lusitanorum asiatico (De cómo es justo el imperio que los portugueses obtienen en Asia) en el que intenta rebatir los argumentos desarrollados por el "desconocido" sobre la libertad de los mares.

Nos interesa mencionar que Freitas (1625/1924, p. 295) define al derecho de gentes como "el derecho natural del hombre", y lo caracteriza de único, a pesar de que, con el tiempo, haya sufrido mudanzas, ya que, según él, el derecho de gentes constituye la naturaleza y condición de las cosas, y no su aprobación o uso introducido más tarde. Cree que se denomina derecho de gentes no tanto porque lo hayan aprobado los hombres, sino, más bien, por cuanto fue en virtud de la razón natural.

Freitas llega a la conclusión de que no es la aprobación subsiguiente al hecho la que crea el derecho de gentes, sino la razón natural que radica en el entendimiento de los hombres todos. Igualmente, reconoce que el consentimiento unánime de los hombres puede suministrar un indicio de gran valor para reputar a una norma como perteneciente al derecho de gentes.

Para Freitas (1625/1924, pp. 295-298) el derecho de gentes comenzó, entonces, con el género humano merced a la lumbre de la razón, pues entendía que los hombres, usando su razón, podían conocer -0 al menos suponeraquellas instituciones venideras. Sin perjuicio de las argumentaciones en las que intenta rebatir los argumentos expresados por parte de Grocio en Mare Liberum, coincide con él en cuanto a que, si el derecho positivo humano tropieza con una resistencia del derecho divino o natural, aquel carece de validez (Freitas, 1625/1924, p. 297).

En opinión del internacionalista Alfred Verdross (1976, pp. 84-87), es a partir de Grocio, cuando la doctrina del derecho internacional se divide en dos importantes ramas: la iusnaturalista pura y el positivismo jurídico puro. La primera creía que la razón era la fuente única del derecho; y la segunda, consideraba al derecho como un mero producto de una voluntad ${ }^{13}$.

13 Entre los primeros autores defensores del puro iusnaturalismo, Verdross incluye al filósofo inglés Thomas Hobbes (1588-1679) y a Samuel Pufendorf (1632-1694). En cuanto a los precursores del positivismo jurídico, en el derecho internacional, el jurista austríaco menciona a Christian Thomasius (1655-1728), Alberico Gentili (1552-1608), Richard Zouche (1590-1660), Wolfgang Textor (16381701), y en especial, a Cornelius van Bynkershoek (1673-1743) y a Johann Jakob Moser (1701-1785). 
A partir de la mitad del s. XVII y hasta inicios del s. XX los autores que se refieren al ius gentium lo hacen siguiendo, de algún modo, los aportes de la Escuela Española o alguna de las visiones de Grocio, e incluso utilizándolo a veces como sinónimo de derecho internacional, o solamente como equivalente a la costumbre jurídica internacional. Continúan siendo una constante a lo largo de estos siglos las referencias al derecho natural como límite y su contraposición con las doctrinas sobre el derecho internacional positivo.

\section{El ius gentium moderno (siglo XX en adelante)}

Con la finalización de la Primera Guerra Mundial y luego de la creación de la Sociedad de Naciones, surge una verdadera comunidad internacional y se hace patente la idea de globalidad. La gran cantidad de tratados internacionales firmados a partir del siglo XX significó el triunfo del positivismo y la aparición de una red de complejas relaciones. El derecho convencional pasa a ser la fuente por excelencia del derecho internacional, quedando la costumbre relegada a un segundo plano. La propia expresión ius gentium comienza a utilizarse cada vez con menos frecuencia y casi de manera exclusiva pasa a ser sinónimo de derecho internacional consuetudinario.

Es conocido que, durante este período, se utilizaron argumentaciones jurídicas para justificar algunas de las atrocidades que desembocaron en la Segunda Guerra Mundial. Como reacción surgen críticas al positivismo más extremo y se produce un renacimiento de algunas teorías del derecho natural.

Una vez finalizado el conflicto bélico mundial se realiza un nuevo intento de cooperación global. Con la gran influencia de los acuerdos surgidos de las conferencias de Dumbarton Oaks (octubre de 1944) y de Yalta (febrero de 1945), el 26 de junio de 1945 finalmente se firma la Carta de San Francisco, por la que se crea la Organización de las Naciones Unidas.

Este nuevo organismo internacional fue creado utilizando como base la coexistencia de dos principios políticos contrapuestos: uno denominado principio de equilibrio, y el otro, el principio de supraordenación. El primero de estos se refleja en la existencia de miembros permanentes del Consejo de Seguridad

Verdross señala, a su vez, que dentro del positivismo jurídico debe distinguirse, entre los autores que no niegan la validez moral del derecho natural (a pesar de limitarse a exponer el derecho internacional positivo), de quienes niegan completamente la existencia del derecho natural, incluso como parte de la moral. Verdross denomina a este último grupo positivista jurídico radical. 
con derecho a veto, esto es, una prerrogativa reservada para unos pocos Estados privilegiados. El segundo principio, es decir, el de supraordenación, se desarrolla en la Asamblea General, que es la caja de resonancia de la verdadera expresión libre y democrática de los distintos sistemas jurídicos, políticos, religiosos e ideológicos del orbe, cuya representatividad le otorga un peso jurídico y moral indiscutido.

Veamos ahora la cuestión específica de las decisiones de la Asamblea General, que se manifiestan a través de resoluciones y declaraciones, y su valor, en relación con el derecho consuetudinario. En opinión del internacionalista Gómez Robledo (2003, pp. 160-165), estas decisiones de la Asamblea General son siempre reconducibles a alguna de las fuentes ya reconocidas del derecho internacional: la costumbre o a los principios generales del derecho. Por eso, para él no tienen en sí el valor de fuente generadora, sino que constituyen fuente esencialmente testificativa. Existen también otros métodos para considerar a las resoluciones de la Asamblea General, entre ellos, Gómez Robledo (2003, pp. 160-165) menciona la tesis defendida por Caicedo Perdomo, para quien, junto a las tres fuentes primarias del derecho internacional (tratado, costumbre y principios generales del derecho) existiría una cuarta fuente que se manifiesta cuando "está presente la comunidad internacional de Estados en su conjunto" (Gómez Robledo, 2003, p. 163). Ello sucedería cuando sesiona la Asamblea General de las Naciones Unidas y a través de conferencias internacionales universales. Gómez Robledo califica esta propuesta de Caicedo Perdomo de verdaderamente revolucionaria y no la comparte, porque entiende que esto significaría llevar las cosas demasiado lejos, al dar lugar a una "costumbre instantánea”, en donde no se vislumbre una reiteración de conductas que reflejen una práctica jurídica consuetudinaria.

Becerra Ramírez (2017, pp. 57-59) explica que la idea de la "costumbre instantánea” surgió en los años sesenta, y se utilizaba como ejemplo las resoluciones que regulan el espacio cósmico aprobadas por la Asamblea General, que en muy poco tiempo se consideraban parte la costumbre internacional, sin una práctica prolongada. En su opinión, esta postura tiene el inconveniente de desviar la atención en algunos casos específicos en donde existe una opinio iuris clara e indudable. Para la jurisprudencia, la práctica no necesariamente debe ser larga en el tiempo (Becerra Ramírez, 2017, p. 58).

Abordemos ahora la cuestión del valor de las resoluciones de la Asamblea General, que se debatió desde su constitución y sigue siendo hoy motivo de discusión doctrinaria. Becerra Ramírez divide a la doctrina actual en tres 
posturas: a) los que consideran que pueden servir como un pronunciamiento sobre la existencia de una costumbre o una nueva forma de creación de costumbre internacional; b) aquellos que entienden que sirve para manifestar la opinio iuris y servir como práctica estatal "colectiva”; y c) aquellos que los ven como una simple recomendación. Destaca el autor, que todos aquellos que niegan el carácter vinculante de estas resoluciones, no por ello rechazan la gran "autoridad jurídica” que tienen muchas de ellas (Becerra Ramírez, 2017, p. 113). El autor concluye, que hay algunas resoluciones de la Asamblea General que no tienen explicación en el marco del art. 38-1, que sería como una “camisa de fuerza que impide considerar al fenómeno de las resoluciones desde otra perspectiva más abierta y acorde con la transformación de las relaciones internacionales a principios del siglo XXI” (Becerra Ramírez, 2017, p. 115).

Debemos ahora hablar del proyecto de conclusiones adoptado por la Comisión de Derecho Internacional sobre la identificación del derecho internacional consuetudinario, que se refiere al valor de las decisiones de la Asamblea General en su 70ª sesión (A/73/10, 2018, pp. 126-170). Este trabajo todavía está en curso, y durante 2019, el proyecto fue sometido en segunda lectura a consideración de la Sexta Comisión de la Asamblea General ${ }^{14}$.

En primer término, la Comisión menciona en sus conclusiones segunda, tercera y cuarta, que existe acuerdo general en cuanto al necesario cumplimiento de dos requisitos esenciales para poder hablar de derecho internacional consuetudinario: una práctica generalizada, y que esta sea aceptada como derecho (opinio iuris). Idéntico criterio tiene al respecto la Corte Internacional de Justicia, cuyas decisiones también facilitan la identificación de costumbres internacionales.

En segundo lugar, la CDI se inclina a establecer que las resoluciones de organismos internacionales y al igual que las provenientes de conferencias intergubernamentales, son decisiones y declaraciones que, por sí solas, no pueden crear normas de derecho consuetudinario. Sin embargo, en la conclusión $\mathrm{N}^{\mathrm{o}} 12$ de este proyecto que venimos analizando, se establece que estas decisiones sí pueden constituir un elemento de prueba de la existencia

\footnotetext{
14 Puede consultarse el documento A/CN.4/724 (2019, pp. 27-29) que contiene un breve informe sobre comentarios emitidos en la Asamblea General de Naciones Unidas sobre el trabajo de la CDI en relación con la identificación del derecho internacional consuetudinario. Se realizó la segunda lectura sobre este tema, habiendo generado aceptación en general de las delegaciones para utilizarlo como orientación práctica para los Estados, los profesionales, los académicos y los jueces. Sin embargo, se dejó de manifiesto que la identificación del derecho internacional consuetudinario debía hacerse de manera autónoma por los tribunales y las cortes de justicia, y no a través de fuentes secundarias, como las que figuraban en el memorando de la Secretaría (A/CN.4/724, 2019, p. 27).
} 
y el contenido de una norma de derecho internacional consuetudinario, o contribuir a su desarrollo. Más aun, también se dice aquí, que pueden reflejar una norma de derecho internacional consuetudinario, pero si se establece expresamente que tal o cual resolución o disposición se corresponde a una práctica general aceptada como derecho (opinio iuris).

Esto significa que debería analizarse caso por caso si ciertas decisiones con mayorías tan abrumadoras, de carácter general, y repetidas en el tiempo, pueden significar que expresan una opinio iuris de obligatoriedad, y que hagan que los Estados se sientan obligados a cumplir, porque fueron aprobadas por mayorías aplastantes. Un estudio pormenorizado de resoluciones del órgano colegiado más representativo de planeta, sería de una gran utilidad a fin de verificar cuáles son estas costumbres jurídicas nacidas de la práctica de los Estados en este ámbito.

Por último, la Comisión se encarga de resaltar el diferente peso que tiene el plenario de la Asamblea General, por la gran participación y la dimensión que adquieren o pueden adquirir resoluciones aprobadas por órganos 0 conferencias de composición más reducida.

\section{Conclusiones}

Después de lo expuesto podemos llegar a algunas conclusiones:

En primer lugar, existe acuerdo generalizado en cuanto a que la costumbre forma parte del sistema de fuentes de derecho internacional y a los requisitos que las prácticas de los Estados deben cumplir para ser consideradas con tal carácter: la persistencia y repetición, junto con la opinio iuris sobre su obligatoriedad, aunque no necesariamente deba tratarse de una práctica prolongada.

En segundo lugar, la evolución histórica de las relaciones internacionales ha provocado que las costumbres, en sentido clásico (ius gentium), que eran predominantes maneras de relacionarse entre los Estados, hayan sido paulatinamente reguladas a través del derecho convencional que es hoy predominante.

Tercero, a pesar de la evolución jurídico-política del abundante derecho convencional interestatal y generado por medio de las organizaciones 
internacionales, en las relaciones internacionales siguen surgiendo costumbres jurídicas internacionales que nacen de las prácticas de los Estados.

En otro orden de cosas, creemos que es de difícil aceptación la idea lisa y llana de que la comunidad reunida en su conjunto pueda constituir una nueva fuente propia del derecho.

Por su parte, la visión de la Comisión de Derecho Internacional, manifestada en su proyecto, restringe notablemente la creación de costumbre por parte de la Asamblea General de Naciones Unidas, al señalar que únicamente lo sería en el caso de que la propia resolución lo diga de manera expresa.

Es nuestra opinión, que esta visión de la Comisión de Derecho Internacional es demasiado estricta al negar la posibilidad de que se genere costumbre internacional a través de las decisiones de la Asamblea General. Parte de la doctrina también defiende esta postura, al entender que ciertas normas internacionales de carácter consuetudinario se verían reflejadas en decisiones de la Asamblea General, al ser suficientemente contundentes y constantes, y que Estados se sienten obligados a cumplir por haber sido aprobadas por mayorías aplastantes.

Deseamos aclarar, que las decisiones que han cumplido o cumplirán con estos requisitos serán seguramente bien escazas, pero importantes, ya que versarán sobre los tópicos del máximo interés para mantener y promover la paz y la protección de los valores esenciales del derecho humanitario y los derechos humanos.

\section{Referencias}

A/73/10 (2018) Informe de la Comisión de Derecho Internacional. 70. ${ }^{\circ}$ período de sesiones (30 de abril a 1 de junio y 2 de julio a 10 de agosto de 2018). Nueva York: Naciones Unidas. Recuperado de https://undocs.org/es/A/73/10 (Acceso: 05/06/2019)

A/CN.4/724 (2019). Informe de la Comisión de Derecho Internacional sobre la labor realizada en $\mathrm{su} 70^{\circ}$ período de sesiones (2018). Resumen por temas, preparado por la Secretaría, de los debates de la Sexta Comisión de la Asamblea General en su septuagésimo tercer período de sesiones. Asamblea General. Nueva York: Naciones Unidas. Recuperado de https://undocs.org/es/A/CN.4/724 (Acceso: 20/05/2020)

Barcia Trelles, C. (1934). Internacionalistas españoles del siglo XVI. Francisco Suárez (1548-1617). Valladolid: Talleres Tipográficos Cuesta, Universidad de Valladolid. 
Becerra Ramírez, M. (2017). Las fuentes contemporáneas del derecho internacional. México: UNAM.

Carta de las Naciones Unidas y Estatuto de la Corte Internacional de Justicia. (1945). San Francisco: Naciones Unidas.

Chrétien, A. (1893). Principes de Droit International Public. T. 1. París: Chevalier-Marescq et Cie. Éditeurs.

Diez de Velasco, M. (2009). Instituciones de Derecho Internacional Público (17 Ed.). Madrid: Tecnos.

Freitas, S. (1925). De cómo es justo el imperio que los portugueses obtienen en Asia, (J. Zurita, Trad.). Valladolid: Universidad de Valladolid.

García del Corral, I. (1892). Cuerpo del derecho civil romano: a doble texto, traducido al castellano del latino, con las variantes de las principales ediciones antiguas y modernas y con notas referencias. T. 4. Barcelona: Kriegel, Hermann y Osenbrüggen.

Gómez Robledo, A. (2003). El ius cogens internacional. Estudio histórico-crítico. México: Universidad Nacional Autónoma de México.

Grocio, H. (1956). De la libertad de los mares (Mare Liberum), estudio preliminary versión española por L. García Arias. Madrid: Instituto de Estudios Políticos.

Grocio, H. (1987). Del derecho de presa. Del derecho de la guerra y de la paz. (P. Mariño Gómez, Trad.). Madrid: Centro de Estudios Constitucionales.

Heffter, A. G. (1857). Le Droit International Public de l'Europe. Berlin: Schroeder.

Langenscheidt (2019, 10 de febrero). Diccionarios en línea. Recuperado de https:// es.langenscheidt.com> (Acceso: 10/02/2019).

Lombardi, G. (1947). Sul concetto di «ius gentium». Roma: Istituto di Diritto Romano.

Martens, G. (1821). Précis du droit des gens moderne de l'Europe, fondé sur les traités et l'usage ( $3^{\circ} \mathrm{Ed}$.). Goettingen: Librairie de Dieterich.

Neumann, L. (1900). Derecho Internacional Público Moderno. Madrid: La España Moderna.

Pereña, L. (1973). La génesis suareciana del ius gentium en Suárez, Francisco, De legibus (II 13-20) de iure gentium, edición crítica bilingüe por L. Pereña, V. Abril \& P. Suñer, Corpus Hispanorum de Pace, Vol. XIV. Madrid: Instituto Francisco de Vitoria.

Pistoriensis, C. (1964). In Codicem et aliquot títulos Primi Pandectorum Tomi, id est, Digesti Veteris, Doctissima Commentaria. Facsimile ed. Francoforti ad Moenum (Sigismundi Feyerabent, 1578), t. 1. Torino: Bottega d'Erasmo.

Pradier-Fondéré, P. (1885). Traité de Droit International Public Européen \& Américain. París: Durant et Pedone-Lauriel Éditeurs.

Puy, F. (2014). Las trampas del lenguaje jurídico y político. México: Editorial Porrúa.

Rivier, A. (1896). Principes du Droit des Gens. T. 2. París: Éditeur Arthur Rousseau.

Soto, D., O.P. (1968). De iustitia et iure (De la justicia y del derecho, en diez libros), Edición facsimilar de la hecha por D. de Soto en 1556. Vol. 2, Lib. III. Madrid: Instituto de Estudios Políticos.

Suárez, F. (1973). De legibus (II 13-20) de iure gentium, edición crítica bilingüe por L. Pereña, V. Abril \& P. Suñer, Corpus Hispanorum de Pace, Vol. XIV. Madrid: Instituto Francisco de Vitoria.

Verdross, A. (1935). Anfechtbare und nichtige Staatsverträge, Zeitschrift für öffentliches Recht, vol. 15, pp. 289-299. Wien: Springer. 
Verdross, A. (1937a). Forbidden Treaties in International Law; Comments on Professor Garner's Report on: The Law of Treaties. The American Journal of International law, vol. 31, $N^{\circ} 4$, pp. 571-577. Washington: The American Society of International Law. Verdross, A. (1937b). Trattati contra bonos mores, Rivista di Diritto Internazionale, vol. XVI, pp. 3-11. Roma: Athenaeum.

Verdross, A. (1976). Derecho Internacional Público (5² Ed.) (Antonio Truyol y Serra, Trad.). Madrid: Biblioteca Jurídica Aguilar.

Vitoria, F. (1967). Relectio de indis o Libertad de los indios, Edición crítica bilingüe por L. Pereña y J. M. Pérez Prendes. Madrid: Corpus Hispanorum de Pace, Consejo Superior de Investigaciones Científicas.

Vitoria, F. (2001). La justicia, estudio preliminar y traducción de Luis Frayle Delgado. Madrid: Tecnos.

Vitoria, F. (2008). Relectio de potestate civili, edición crítica por Jesús Codero Pando. Madrid: Corpus Hispanorum de Pace, Consejo Superior de Investigaciones Científicas. 